\title{
An Immunologic Approach to Induction of Epidermal Growth Factor Deficiency: Induction and Characterization of Autoantibodies to Epidermal Growth Factor in Rats
}

\author{
LASSE RAABERG, EBBA NEXØ, STEEN S. POULSEN, AND \\ PER E. JØRGENSEN \\ Department B, Institute of Medical Anatomy, The Panum Institute, Blegdamsvej 3, DK-2200 Copenhagen, \\ Denmark [L.R., S.S.P.], and Department of Clinical Biochemistry, University Hospital of Aarhus, \\ DK-8000 Aarhus, Denmark [L.R., E.N., P.E.J.]
}

\begin{abstract}
ABS
Epidermal growth factor (EGF) in pharmacologic doses is
able to induce growth and development in the fetus and the
newborn. To investigate the opposite situation, the effects of
insufficient amounts of EGF during development, we wanted to
establish an in vivo model with a state of EGF deficiency. This
was attempted by induction of autoimmunity to EGF in rats.
Twenty rats were immunized with EGF. Fifteen of these devel-
oped autoantibodies against EGF, which, as judged by Scatchard
analysis, had a median apparent affinity constant of $14 \times 10^{9}$
$\mathrm{~L} /$ mol and a median concentration of binding sites of $20 \times 10^{-9}$
mol/L. The antibodies recognized purified EGF from the sub-
mandibular glands (6 kD) and from urine (45 kD) and further
native EGF in saliva and urine. The cross-reactivity toward
transforming growth factor- $\alpha$ was below $3 \%$. Binding of EGF by
antibodies inhibited its binding to the EGF-receptor by approx-
imately $97 \%$ in vitro. Investigation of in vivo metabolism of
\end{abstract}
EGF is a 53-amino acid peptide, discovered by Stanley Cohen (1), with an ability to accelerate eyelid opening and incisor eruption in newborn mice. Its human counterpart was isolated from urine and initially named urogastrone, because it could inhibit gastric acid secretion (2). Today it is known that EGF is produced in several organs, including the submandibular glands, the respiratory system, the kidneys, and the digestive tract $(3,4)$. Its receptor has been identified in most organs studied (5). EGF is able to induce growth and differentiation,

\footnotetext{
Received December 28, 1993; accepted January 9, 1994.

Correspondence: Lasse Raaberg, M.D., Ph.D., Institute of Medical Anatomy, Dept B, Blegdamsvej 3, DK-2200 Copenhagen N, Denmark.

Reprint requests: Ebba Nexø, M.D., Dr.med.Sci., Department of Clinical Biochemistry, KH, University Hospital of Aarhus, DK-8000 Aarhus C, Denmark.

Supported by the Nordisk Insulin Foundation Committee (L.R.), The Danish Cance Research Foundation (E.N.), The Danish Biotechnology Center for Neuropeptide Research (S.S.P.), The Boel Foundation, and the Danish Medical Research Council (12-9312)
}

antibody-bound ${ }^{125}$ I-EGF confirmed these results, that is, the antibodies were able to inactivate EGF. The adult rats were unaffected by the induction and presence of autoantibodies, and the EGF-containing organs did not show any histologic signs of inflammation or tissue damage. Furthermore, as judged by immunohistochemistry, no major changes in the distribution and tissue concentration of EGF were seen in the adult rat. These results show that it is possible to induce homologous antibodies that can inhibit the binding of EGF to its receptor and further suggest that circulatory EGF is of no physiologic importance in the healthy, adult rat. (Pediatr Res 37: 169-174, 1995)

\section{Abbreviations}

EGF, epidermal growth factor

NGF, nerve growth factor

TGF- $\alpha$, transforming growth factor- $\alpha$ and at an early stage it was suggested that it participates in the regulation of fetal development $(6,7)$.

Most results concerning a possible physiologic role for EGF have been obtained by injection of pharmacologic doses of the peptide. Because EGF is synthesized in several organs and is believed to act locally, it is impossible to induce EGF deficiency by surgery. A different approach is to induce an immunologic EGF deficiency. This technique was introduced by Gorin and Johnson (8), who immunized rats with mouse NGF and showed that the offspring had the predicted developmental defects, whereas the adult immunized rats were unaffected. Concerning EGF, only passive immunization, in a heterologous system, has been used so far. For example, the injection of rabbit anti-mouse EGF into newborn mice resulted in an increased perinatal mortality (9).

The purpose of the present study was to induce autoimmunity against rat EGF, describe the induced antibodies, and describe possible effects of the autoimmunity against EGF in the adult female rat. 


\section{METHODS}

Immunization protocol. Twenty female Wistar rats (Pan: Wist) aged 10-11 wk were immunized by intradermal injection of $1 \mathrm{nmol}$ of rat EGF in complete Freund's adjuvant. This was followed by three booster injections at an interval of $14 \mathrm{~d}$. For booster injections, $0.5 \mathrm{nmol}$ of rat EGF in complete Freund's adjuvant was used (8). Two control groups were used. In one group, the rats were immunized with physiologic saline and Freund's complete adjuvant according to the same scheme, and in the last group the rats were not immunized. Six rabbits were immunized according to the same scheme, except that a dose of $10 \mathrm{nmol}$ of rat EGF was used for the first immunization and a dose of $10 \mathrm{nmol}$ of EGF and Freund's incomplete adjuvant for booster injections.

Observations. During the immunization period, the rats were observed for signs of illness or failure to thrive. Another group of rats were weighed weekly during the immunization period. To evaluate the amounts of EGF excreted in the urine, the animals were placed in metabolic cages and their urine collected for $24 \mathrm{~h}$. Urinary creatinine was assessed by the Jaffe method with an SMAC (Simultaneous Multiple Analyzer with Computer) (Technicon Instruments, Tarrytown, NY), and urinary EGF was quantified by RIA (10).

Antibodies. Ten d after the third and the fourth immunization, $400 \mu \mathrm{L}$ of blood from each rat were collected from the tail. The blood was allowed to clot and thereafter centrifuged for $10 \mathrm{~min}$ at $1500 \times \mathrm{g}$. The ability to bind 6-kD EGF purified from rat submandibular glands and $45-\mathrm{kD}$ EGF purified from rat urine was determined by incubation of $100 \mu \mathrm{L}[\sim 20000$ $\operatorname{cpm}(\sim 40 \mathrm{fmol})]$ of ${ }^{125}$ I-EGF $(6 \mathrm{kD}$ or $45 \mathrm{kD})$ with $100 \mu \mathrm{L}$ of rat serum in dilution $(1: 10,1: 100,1: 1000$ and 1:10000) overnight. Free and bound tracers were separated by polyethylene glycol (11). The unbound fraction was assessed in a $y$-counter (Riacounter, Mølsgaard Medical, Hørsholm, Denmark). Only antisera obtained after the fourth immunization, which at a dilution of $1: 10$ bound more than $60 \%$ of added labeled EGF, were used for further analyses.

RIA for rat EGF. The RIA for rat EGF that uses rabbit anti-rat EGF (813) has previously been described (10). To characterize the rat anti-rat EGF antibodies, we performed RIA analyses in which the rabbit anti-rat EGF serum was replaced by rat anti-rat EGF serum. EGF purified from the submandibular glands was used as labeled peptide and calibrator (0)-4.8 $\mathrm{pmol} / \mathrm{mL}$ ). The following samples were examined: rat saliva [1.7 pmol EGF/mL (determined by RIA using rabbit anti-rat EGF (10)], rat urine [2.5 pmol EGF/mL (determined by RIA)], and rat TGF- $\alpha[10 \mathrm{pmol} / \mathrm{mL}$ (concentration supplied by the manufacturer)] (Peninsula, Merseyside, UK). From the calibration curves, Scatchard plots were constructed, and the affinity constant and the number of binding sites were estimated (12).

In vitro receptor binding of EGF antibody complexes. Radioreceptor assay was performed as previously described (1.3). In bricf, antiserum or nonimmune serum (100 $\mu \mathrm{L}$, diluted 1:10) was incubated with $100 \mu \mathrm{L}$ of ${ }^{125} \mathrm{I}-\mathrm{EGF} \mid \sim 20000 \mathrm{cpm}$ $(\sim 40$ fmol)]. After $2 \mathrm{~h}$ at room temperature, 100$) \mu \mathrm{L}(1 \mathrm{mg}$ protein $/ \mathrm{mL}$ ) of human placenta membranes were added and the incubation was continued overnight. The receptor-bound com- plexes were separated from unbound antibody-EGF complexes by filtration through $0.2-\mu \mathrm{m}$ filters (SM 11107 Sartorius, Göttingen, Germany). Filters (containing the receptor-bound fraction) were counted in a $\gamma$-counter. For determination of the maximal binding of labeled EGF to the membranes, the immune serum was replaced by PBA [0.1 M phosphate buffer, $0.1 \%$ human albumin (Behringwerke, Marburg, Germany), pH 8.0], and for determination of nonspecific binding of labeled EGF to the filters, the placenta membranes were replaced by PBA. The nonspecific binding of the tracer to the filters was below $2.5 \%$, and the maximal binding of EGF to the membranes was $65 \%(55-67 \%)$.

Metabolism of EGF antibody complexes. A S-200 Sephacryl column $(1.0 \times 45 \mathrm{~cm})$ (Pharmacia, Uppsala, Sweden) was packed according to the manufacturer's instructions. The column was calibrated with Dextran Blue (Pharmacia), human albumin (Behringwerke), ${ }^{125} \mathrm{I}-\mathrm{EGF}(6 \mathrm{kD})$, and ${ }^{22} \mathrm{NaCl}$ (Amersham, Buckinghamshire, UK).

${ }^{125}$ I-EGF $\left(20 \times 10^{6} \mathrm{cpm}\right)$ was preincubated for $3 \mathrm{~h}$ with 100 $\mu \mathrm{L}$ of rat anti-rat EGF, applied to the S-200 Sephacryl column, and run in $0.9 \% \mathrm{NaCl}$ at a flow rate of $0.8 \mathrm{~mL} / 2.5 \mathrm{~min}$. All ${ }^{125}$ I-EGF eluted in one peak near the void volume, indicating that all the labeled EGF was bound to rat anti-rat EGF. The peak fractions were pooled.

In vivo metabolism was studied as previously described (14); in brief, doses of approximately $10^{6} \mathrm{cpm}(2 \mathrm{pmol})$ of ${ }^{125}$ I-EGF complexed to rat anti-EGF were injected into the inferior vena cava of four nonimmunized female Wistar rats weighing approximately $300 \mathrm{~g}$. The rats were anesthetized with Brietal (Metohexital, Eli Lilly and Co., Indianapolis, IN). Blood samples were drawn from the inferior vena cava $1 \mathrm{~min}, 10 \mathrm{~min}, 30$ $\min , 1 \mathrm{~h}, 2 \mathrm{~h}, 4 \mathrm{~h}, 8 \mathrm{~h}, 16 \mathrm{~h}$, and $24 \mathrm{~h}$ after the injection. The abdominal wall was sutured and the rats were allowed to regain consciounincss betwecn the last five samples. For cominañisoñ a control group $(n=6)$ received an injection of ${ }^{125}$ I-EGF, and blood samples were drawn after $1,2,3,5,10$, and $15 \mathrm{~min}$. The samples were counted in a $\gamma$-counter and the 24-h samples were run on the S-200 Sephacryl column as described above to examine whether the radioactivity represented antibody-bound EGF.

$\boldsymbol{E} \boldsymbol{G} \boldsymbol{F}$. Six-kD EGF was purified from rat submandibular glands as previously described. The peptide was pure as judged from SDS polyacrylamid gels (10). Forty-five-kD EGF from rat urine was purified as described (11). ${ }^{125}$ I-EGF was prepared by the chloramine- $T$ method (sp act, $450-500 \mathrm{cpm} / \mathrm{fmol} E G F$ ), as described elsewhere (14).

Histologic examinations. Tissue from adult rats was fixed by immersion. Bouin's fixative without acetic acid was used. The tissues were postfixed in $70 \%$ ethanol and embedded in paraffin. The submandibular glands, the lungs, the kidneys, the small intestine, the liver, and the spleen were investigated. Histologic sections were stained with periodic acid-Schiff, hematoxylin, and aurantia and examined independently by two investigators.

Immunohistochemistry. Five- $\mu \mathrm{m}$ sections from the submandibular glands, the lungs, the kidneys, and the duodenum were investigated. Antisera raised in rabbits against 6-kD EGF purified from rat submandibular glands (ab 3123) or purified 
from human urine [ab 1589 (15)] were used. The immunoreaction was visualized by the peroxidase-antiperoxidase technique according to Sternberger (16). The sections were slightly counterstained with hematoxylin and examined independently by two investigators.

Calculations. Results are expressed as median with range in parentheses, unless otherwise stated. For comparison of groups, the Mann-Whitney U test was used. For comparison of the development of titers after the third and fourth immunizations, the Wilcoxon-Pratt test for paired data were used. The program "Ligand" was used for estimation of the apparent affinity constant and the concentration of binding sites (17).

\section{RESULTS}

Of the 20 rats immunized with rat EGF, 15 developed antibodies, which at a dilution of 1:10 were able to bind greater than $60 \%$ of exogenous iodinated EGF, after the fourth immunization (Fig. 1). None of the sera from control-immunized rats bound ${ }^{125}$ I-EGF. The titers were significantly better after four immunizations than after three $(p<0.003)$. In addition to the binding of $6-\mathrm{kD}$ EGF, the antibodies also bound $45-\mathrm{kD}$ EGF purified from rat urine (Fig. 2). All of six rabbits immunized four times with rat EGF produced antibodies.

The apparent affinity constant toward $6-\mathrm{kD}$ EGF purified from the submandibular glands was estimated for antiserum from 15 rats and six rabbits using Scatchard plots (Table 1). Scatchard plots that indicated two classes of binding sites were obtained for serum from nine rats. None of the Scatchard plots for rabbit sera indicated two classes of binding sites. The

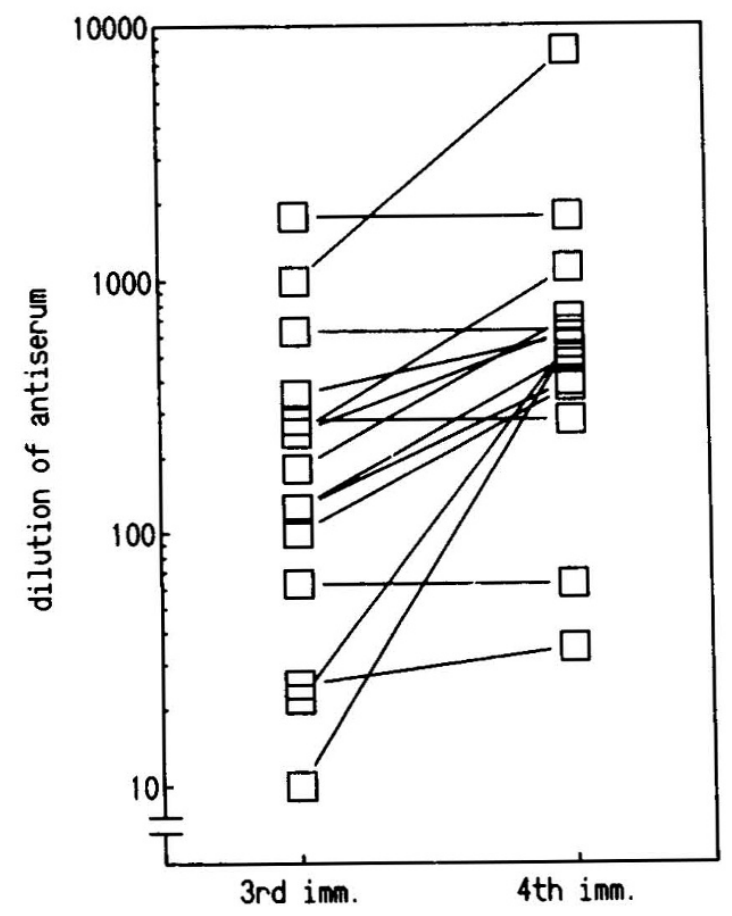

Figure 1. Binding of rat EGF by rat anti-rat EGF. The dilution of rat antisera that bound $50 \%$ of added labeled rat EGF (titer) after the third and fourth immunizations. The titer was significantly higher after the fourth immunization. $y$ axis: titer, logarithmic scale.

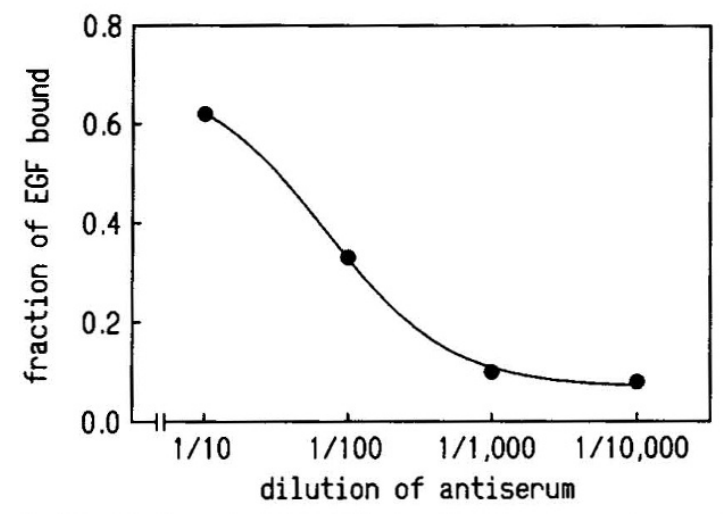

Figure 2. The binding of $45-\mathrm{kD}$ EGF purified from rat urine at different dilutions of a rat antiserum. $x$ axis: dilution of antiserum. $y$ axis: fraction of added EGF bound by the antiserum.

Table 1. Apparent affinity constant (Ka) and number of binding sites for rat and rabbit antibodies against rat EGF

\begin{tabular}{|c|c|c|c|c|}
\hline & \multicolumn{2}{|c|}{ High-affinity binding sites } & \multicolumn{2}{|c|}{ Low-affinity binding sites } \\
\hline & $\begin{array}{c}\mathrm{Ka} \\
\left(10^{9} \mathrm{~L} / \mathrm{mol}\right)\end{array}$ & $\begin{array}{c}\text { No. of } \\
\text { binding sites } \\
\left(10^{-9} \mathrm{~mol} / \mathrm{L}\right)\end{array}$ & $\begin{array}{c}\mathrm{Ka} \\
\left(10^{9} \mathrm{~L} / \mathrm{mol}\right)\end{array}$ & $\begin{array}{c}\text { No. of } \\
\text { binding sites } \\
\left(10^{-9} \mathrm{~mol} / \mathrm{L}\right)\end{array}$ \\
\hline $\begin{array}{l}\text { Rat } \\
(n=15)\end{array}$ & $\begin{array}{c}14 \\
(2-70)\end{array}$ & $\begin{array}{c}20 \\
(2-480)\end{array}$ & $\begin{array}{c}0.2 \\
(0.02-1) \\
n=9\end{array}$ & $\begin{array}{c}320 \\
(19-8500) \\
n=9\end{array}$ \\
\hline $\begin{array}{l}\text { Rabbit } \\
(n=6)\end{array}$ & $\begin{array}{c}33 \\
(14-67)\end{array}$ & $\begin{array}{c}500 \\
(36-1420)\end{array}$ & & \\
\hline
\end{tabular}

Data are given as median, with range in parentheses. For nine of the rats, a second class of binding sites was indicated by the Scatchard plots.

apparent affinity constant and the number of binding sites are shown in Figure 3 and summarized in Table 1.

The antisera recognized endogenous EGF present in saliva and urine in a comparable although not identical manner (Fig. 4). TGF- $\alpha$ at a concentration of $10 \mathrm{pmol} / \mathrm{mL}$ was measured as $<0.3 \mathrm{pmol} / \mathrm{mL}$.

To assess whether antibody-bound EGF could bind to the EGF receptor, ${ }^{125}$ I-EGF was preincubated with the antisera before receptor binding. This caused a median of $97 \%$ (90$98 \%$ ) inhibition of the receptor binding in vitro for the rat antisera and a median of $91 \%(85-96 \%)$ inhibition for the rabbit sera.

To study the biologic significance of the antibodies, we compared the disappearance of iodinated EGF and iodinated EGF attached to rat anti-EGF in the rat. Although iodinated EGF disappears from the circulation within minutes, more than $40 \%$ of the label is still present after $4 \mathrm{~h}$ if iodinated EGF is bound to the antibody (Fig. 5). Upon gel chromatography of the 24-h samples from a rat injected with EGF bound to anti-EGF, the radioactivity eluted near the void volume, indicating that the tracer was still antibody bound (data not shown).

The histologic examination of tissues from the immunized animals did not reveal any signs of inflammation or other abnormalities in the organs that produce EGF, i.e. the submandibular glands, the kidneys, the Brunner's glands of the duodenum, and the lungs. Neither did the liver, which is rich in EGF receptors, show any abnormalities. 
a

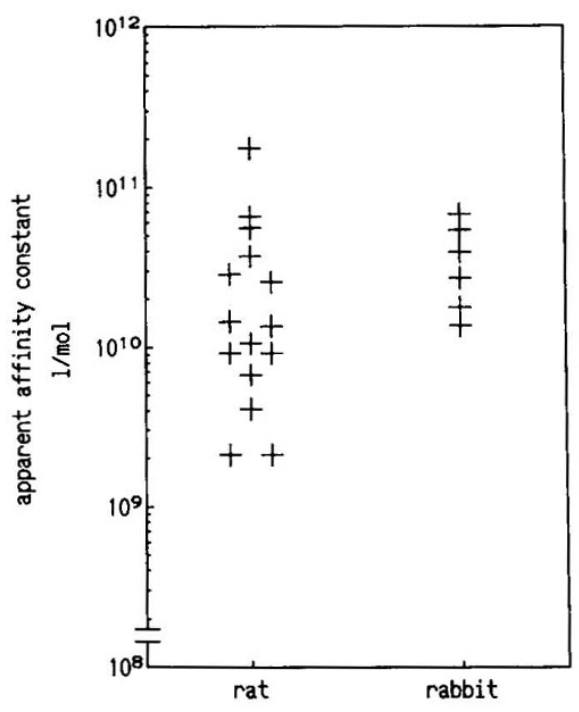

C

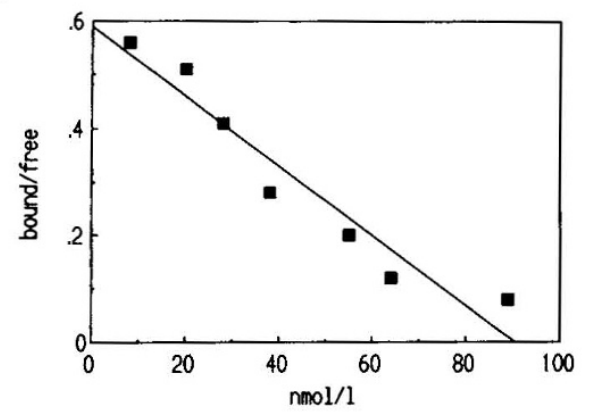

b

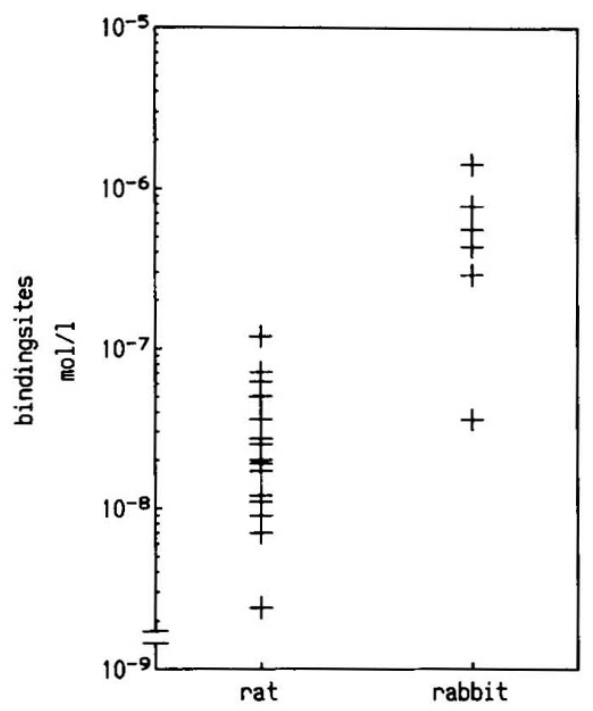

d

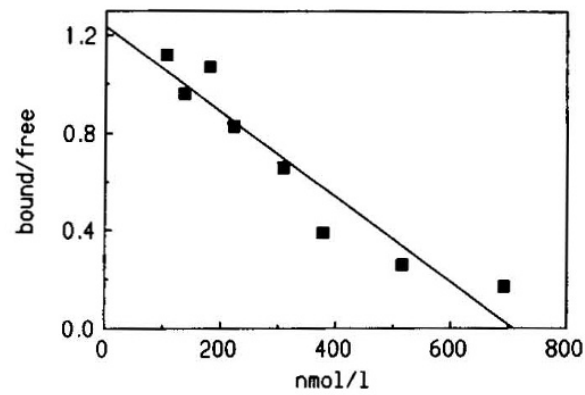

Figure 3. Characterization of anti-rat EGF antibodies raised in rats and rabbits. $a$, The apparent affinity constant for binding of rat EGF to rat and rabbit anti-serum is within the same range. $y$ axis: logarithmic scale. $b$, The number of binding sites for rat EGF to rat and rabbit anti-rat EGF serum. The concentration of binding sites is approximately 10 times higher in rabbit serum than in rat serum. $y$ axis: logarithmic scale. $c$ and $d$, Scatchard plot of a typical antiserum from an EGF-immunized rat $(c)$ and an EGF-immunized rabbit $(d)$.

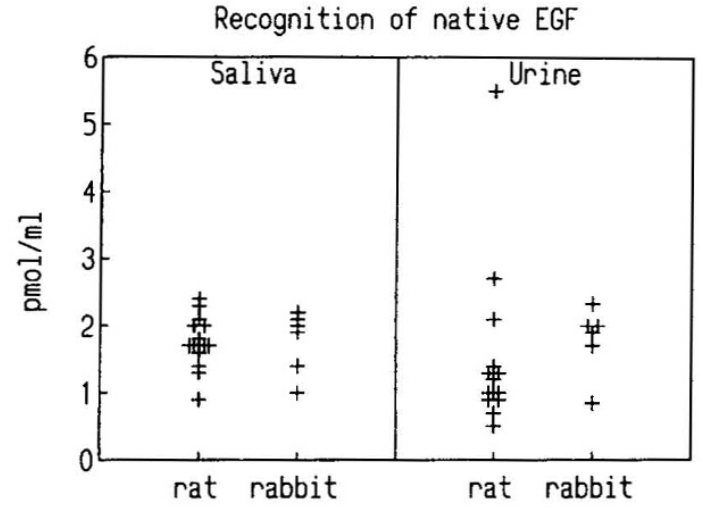

Figure 4. EGF in rat saliva and urine, determined by RIA that uses rat anti-EGF antibodies (rat, $n=15$ ) and rabbit antibodies (rabbit, $n=6$ ). Labeled peptide and calibrator were prepared from rat submandibular glands.

Immunohistochemical localization of EGF and the staining intensity were similar in tissues from immunized rats and control rats. The EGF immunized animals had, during the immunization period, the same growth rate as the rats immunized with saline and Freund's adjuvant [median weight gain in percent of initial weight: $27 \%(n=5)$ versus $21 \%(n=4)$; $p=0.11]$.

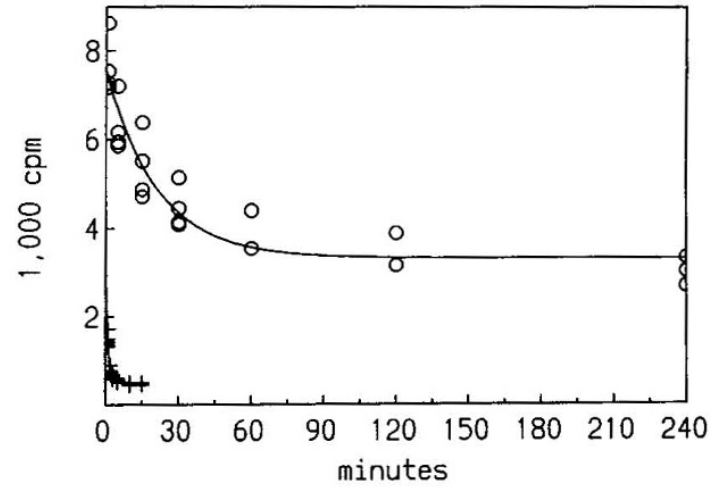

Figure 5. Disappearance of antibody-bound ${ }^{125}$ I-EGF $(O)(n=4)$ and free ${ }^{125} \mathrm{I}-\mathrm{EGF}(+)(n=6)$ from blood after i.v. injection. $x$ axis: time from injection of the radioactivity. $y$ axis: cpm present in $0.2 \mathrm{~mL}$ of blood.

Urine samples from the rats immunized with EGF and nonimmunized rats showed no difference in 24-h urine output [16.4 $\mathrm{mL}$ versus $14 \mathrm{~mL}$ (medians); $p=0.93$ ], in urinary EGF concentrations $[19.0 \mathrm{pmol} / \mathrm{mL}$ versus $20.8 \mathrm{pmol} / \mathrm{mL}$ (medians); $p=0.92]$, or urinary creatinine concentrations [396 $\mu \mathrm{mol} / \mathrm{mL}$ versus $436 \mu \mathrm{mol} / \mathrm{mL}$ (medians); $p=0.83]$. 


\section{DISCUSSION}

To establish an experimental condition of EGF deficiency, we have investigated the possibility of inducing autoantibodies against EGF. The immunization protocol we used gave rise to production of EGF antibodies in the majority of the rats immunized with EGF. With respect to affinity constant, the rat antisera were comparable to EGF antibodies induced in rabbits, whereas the concentration of the high-affinity binding sites was approximately 10 times lower in the rats.

Although there were minor variations in the specificity of the antibodies from individual rats and rabbits, all antisera recognized purified 6-kD rat submandibular EGF, 45-kD rat urinary EGF, and endogenous EGF present in saliva and urine. This indicates two things. First, the antibodies do not recognize the aminoterminal sequence of 6-kD EGF, because this sequence is blocked in 45-kD EGF, and second, the rat antibodies will react with endogenous EGF provided EGF and the antibodies are present in the same compartment. It is therefore worth noting that the urinary excretion of EGF is unchanged in the immunized animals. This adds to the increasing amount of evidence indicating that all urinary EGF is produced in the kidneys and excreted directly into the urine. Should a significant part of the urinary EGF be derived from the circulation, one would expect a decrease in the output of urinary EGF, inasmuch as EGF in the circulation is likely to attach to the antibodies and therefore not be filtered into the urine.

Binding of EGF to antibodies almost totally abolished the binding of EGF to its receptor in vitro. That is, we expected the antibody-bound EGF to be inactivated. This was further substantiated by the in vivo experiment. The antibody-bound EGF was present in the circulation substantially longer than free EGF. In other words, antibody-bound EGF is not bound to its cellular receptors as is free EGF. The results indicate that any supposed endocrine or paracrine effect of EGF is likely to be affected by the presence of autoantibodies against EGF.

We did not observe any major changes in the immunized animals concerning growth rate, histologic appearance of EGFproducing tissues, and immunohistochemical localization of EGF. We believe that two assumptions can be made from these results. First, in the healthy adult rat, circulatory EGF is absent or unimportant. This is in accord with our previous inability to detect EGF in rat plasma (18). Second, the EGF-producing cells do not present EGF as a membrane-bound molecule toward an interstitial fluid that contains anti-EGF.

Gene knockouts are another way to obtain growth factor deficiency. Animals with EGF gene knockouts have not been reported, but recently a gene knockout has been published for TGF- $\alpha$, another peptide that acts via the EGF receptor. Mice with TGF- $\alpha$ null mutations showed only minor abnormalities in the hair follicles and the eyes during development. In agreement with our EGF receptor hypostimulation, no major effects were observed in the adult mice $(19,20)$.

Our findings of no major effects on the adult autoimmune rat are in accord with comparable studies with $\operatorname{NGF}(8,21)$. Gorin and Johnson (8) were unable to find effects of autoimmunity toward NGF.
In contrast to results obtained in adult animals, several authors have described striking effects of antibodies to growth factors in the fetus and the newborn animal. The use of antibodies to inactivate growth factors was introduced by Levi-Montalcini and Angeletti (22). They injected rabbit antimouse NGF into newborn animals and showed a striking action on the sympathetic ganglia. Later, Gorin and Johnson (8) introduced active immunization. They immunized rats with mouse NGF and obtained antibodies that cross-reacted with rat NGF. The immunized animals were unaffected, whereas the offspring, as expected, were seriously affected. It has been shown that antibodies are transferred to the rat fetus during the last part of pregnancy and to the suckling rat by way of the milk (23). Concerning EGF, Tsutsumi and Oka (9) have shown that injection of rabbit anti-mouse EGF into pregnant mice caused increased perinatal mortality. Bereseth (24) and Green et al. (25) have used addition of rabbit anti-EGF to milk and shown a delayed maturation of the digestive tract.

In conclusion, we have developed autoimmunity against EGF in the rat. In the light of work performed with NGF, we believe that this autoimmune model will be useful for the study of a possible physiologic role for EGF in the fetus.

Acknowledgments. The authors thank Kamma Velin, Mette Wolf Madsen, Marianne Rye Hansen, Lotte Bakhøj, and Trine Grainger for technical assistance and Grazyna Hahn for photographic assistance.

\section{REFERENCES}

1. Cohen S 1987 Epidermal growth factor. In Vitro Cell Dev Biol 23:239-245

2. Gregory H 1975 Isolation and structure of urogastrone and its relation to epidermal growth factor. Nature 257:325-327

3. Poulsen SS, Nexø E, Olsen PS, Kirkegaard P 1986 Immunohistochemical localization of epidermal growth factor in rat and man. Histochemistry 85:389-394

4. Raaberg L, Nexø E, Damsgaard Mikkelsen J, Poulsen SS 1988 Immunohistochemical localization and developmental aspects of epidermal growth factor in the rat. Histochemistry $89: 351-356$

5. Fisher DA, Lakshamanan $\mathbf{J} 1990$ Metabolism and effects of epidermal growth factor and related peptides in mammals. Endocr Rev 11:418-442

6. Catterton WZ, Escobedo MB, Sexson WR, Grey ME, Sundell HW, Stahlman MT 1979 Effects of epidermal growth factor on lung maturation in fetal rabbit. Pediatr Res 13:104-108

7. Lebenthal E, Leung Y-K 1979 Epidermal growth factor (EGF) and the ontogeny of the gut. J Pediatr Gastroenterol Nutr 6:1-4

8. Gorin PD, Johnson EM 1979 Experimental autoimmune model of nerve growth factor deprivation: effects on developing peripheral sympathetic and sensory neurons. Proc Natl Acad Sci USA 76:5382-5386

9. Tsutsumi O, Oka T 1987 Epidermal growth factor deficiency during pregnancy causes abortion in mice. Am J Obstet Gynecol 156:241-244

10. Olsen PS, Nexø E 1983 Quantitation of epidermal growth factor in the rat. Identification and partial characterization of duodenal EGF. Scand J Gastroenterol 18:771776

11. Nexø E, Jørgensen PE, Thim L, Roepstorf P 1990 Purification of a low and a high molecular weight form of epidermal growth factor from rat urine. Biochim Biophys Acta 1037:388-393

12. Scatchard G 1949 The attraction of proteins for small molecules and ions. Ann NY Acad Sci 51:660-672

13. Nexø E, Lamberg SI, Hollenberg MD 1981 Comparison of a receptor binding assay with a radioimmunoassay for measuring epidermal growth factor-urogastrone in urine. Scand J Clin Lab Invest 41:577-582

14. Jørgensen PE, Poulsen SS, Nexø E 1988 Distribution of i.v. administered epidermal growth factor in the rat. Regul Pept 23:161-169

15. Nexø E, Olsen PS, Hansen FH 1984 Purification of human epidermal growth factor-urogastrone by immunoaffinty chromatography. In: Peeters $\mathrm{H}$ (ed) Protides of the Biological Fluids. Pergamon Press, New York, pp 1113-1115

16. Sternberger L 1974 Immunocytochemistry. Wiley and Sons, New York, pp 104-169

17. Munson PJ, Rodbard D 1980 A versatile computerized approach for characterization of ligand-binding systems. Anal Biochem 107:220-239

18. Jørgensen PE, Rasmussen TN, Olsen PS, Raaberg L, Poulsen SS, Nexø E 1990 Renal uptake and excretion of epidermal growth factor from plasma in the urine. Regul Pept 28:273-281 
19. Mann BC, Fowler KJ, Gabriel A, Nice EC, Williams EL, Dunn AR 1993 Mice with a null mutation of the TGF- $\alpha$ gene have abnormal skin architecture, wavy hair and curly whiskers and often develop corneal inflammation. Cell 73:249-261

20. Luetteke NC, Qui TH, Peiffer RL, Oliver P, Smithies O, Lee DC 1993 TGF $\alpha$ deficiency results in hair follicle and eye abnormalities in targeted and waved-1 mice. Cell 73:263-278

21. Johnson EM, Gorin PD, Brandeis LD, Pearson J 1980 Dorsal root ganglion neurons are destroyed by exposure in utero to maternal antibodies to nerve growth factor. Science 210:916-918
22. Levi-Montalcini R, Angeletti PU 1961 Growth control of the sympathetic system by a specific protein factor. Q Rev Biol 36:99-108

23. Brambell FW 1970 Frontiers of Biology, Vol 18. Elsevier, New York

24. Bereseth CL 1987 Enhancement of intestinal growth in neonatal rats by epidermal growth factor in milk. Am J Physiol 253:G662-G665

25. Green HL, Moore MC, Said HM, Ghishan FK, Orth DN 1987 Intestinal glucose transport in suckling rats fed artificial milk with and without epidermal growth factor. Pediatr Res 21:404-408 